EDITORIAL

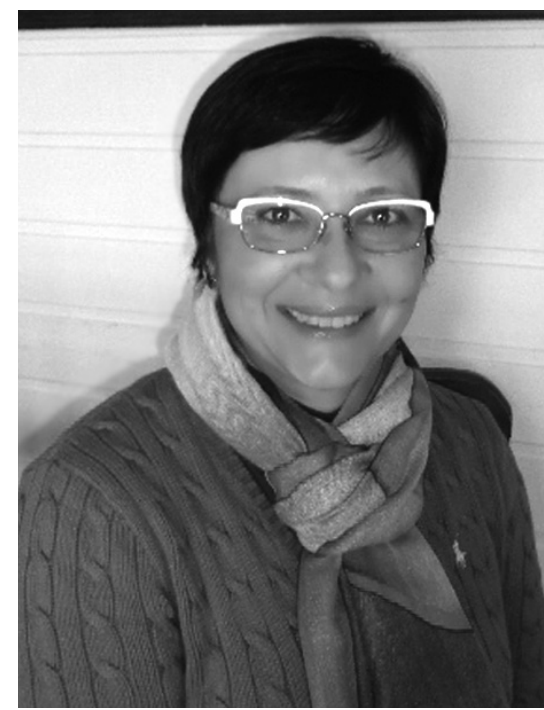

(C) Marcia Regina Cubas

${ }^{1}$ Pontifícia Universidade Católica do Paraná, Programa de Pós-Graduação em Tecnologia em Saúde, Curitiba, PR, Brasil.

m.cubas@pucpr.br

\section{Ensuring a unified and cross-cultural nursing language system: the challenge faced by nursing terminology development}

Marcia Regina Cubas ${ }^{1}$

Developing standardized nursing terminologies demands commitment from peers and a collective effort. The universal use of these terminologies is fully justified given the diversity of practices and cultural contexts, both nationally, in a heterogeneous country like Brazil, and internationally. Unified terminologies are formed in distinct cultures and should encompass all contexts. Indeed, this was the ambitious plan of the International Council of Nurses, the organization responsible for the International Classification for Nursing Practice (ICNP ${ }^{\circledR}$ ).

The consensus on the naming of terms and defining their meaning is determined by nursing professional development specialties, which are influenced by culture, the organization of a society, and by the hegemonic model of health care.

The use of unified terminology should consider culture, social organization, medical practices and the particularities of the professionals that use these technical terms ${ }^{(1)}$.

As with other terminologies, the source language of the set of terms and meanings contained in the $\mathrm{ICNP}^{\circledR}$ is English. Language is a system which represents the words and rules understood by a given linguistic community during the communication process. When the classification is used in countries whose official language is not the source language, it is necessary to carry out a translation and cultural adaptation of the terms. This is not any easy task and is not always a participatory process.

Numerous terms used in nursing are common to all contexts and professional domains and do not raise doubts. These common terms do not raise doubts when submitted to the translation procedure. When the terminology includes a word related to a part of the body, such as the arm, the term is named, represented and understood as part of the upper limb in all cultures and professional contexts, meaning that the cross-cultural adaption of this term, as well as detailing its definition, is unnecessary; suffice it to say that the arm is a body region.

However, this logic does not apply to other sets of terms. For example, in countries that share the same language, such as Brazil and Portugal, a single translation from English to Portuguese may not contemplate the differences in meaning that arise from the historical transformation of the language and culture. Cross-cultural adaption is therefore necessary because the historicity and particular cultural roots of each country result in different forms of understanding and acceptance of the proposed terms, which invariably are not translated and understood in the same way.

Phenomena that are strongly influenced by culture and the organization of social groups are immersed in complexity. Studies of the applicability of the terminological subsets of $\mathrm{ICNP}^{\circledR}$ for the palliative care for a dignified death corroborate this fact ${ }^{(2-4)}$.

Standardizing nursing interventions before death may not take into account cultures such as that of Thailand, where Buddhism is the religion of almost the entire population. Here, death is a welcome phenomenon and nurses have the task of promoting family discussion and encouraging family members to say goodbye ${ }^{(2)}$. 
In the context of care for a dignified death, Thai nurses confirm that incorporating religious and cultural knowledge into their professional activities is particularly important ${ }^{(2)}$, while Hindu nurses suggest including holistic care and Yoga for pain management ${ }^{(3)}$, and South Korean nurses highlight that establishing trust is essential ${ }^{(4)}$.

Cross-cultural adaption also requires knowledge about the health system and its care models, since professional practice is determined by policies and hegemonic and counterhegemonic movements occurring in given contexts. Brazilian nurses confirm that interventions based on the National Humanization Policy should be a priority in care for a dignified death, and therefore any evaluation of this subset in Brazil must include this hypothesis.

In Brazil, it is expected that nursing practices in primary health care settings are anchored on the principles of the Unified Health System and the conceptual bases of public health which seek to overcome the biomedical model of care. In this way, standardized and cross-cultural terminologies that seek to represent the nursing practice in Brazil must be strengthened with the presence of phenomena which originate in this practice and the view of the world held within the public health system. An illustrative example is the fact that the ICNP ${ }^{\circledR}$ mentions the word vulnerability only once throughout the definitions of its terms suggests that its ability to contextualize socially constructed phenomena may be limited.

The fact that one of the objectives of these terminologies is to support the clinical reasoning process and anchor the naming of phenomena relevant to the field is equally important ${ }^{(5)}$. Therefore, providing breadth in the $\mathrm{ICNP}^{\circledR}$ to support epidemiological reasoning and anchor the naming of socially constructed phenomena may contribute to achieving unified and cross-cultural representativeness.

In the beginning of this editorial I affirmed that the construction of nursing terminology is the fruit of the commitments made by peers and collective efforts. Therefore, to meet the challenges presented here, the nursing profession must take effective actions to contribute towards the inclusion of terms in the $\mathrm{ICNP}^{\circledR}$ and discuss the breadth and limitations of the definitions provided for the terminology.

\section{REFERENCES}

1. Clares JWB, Freitas MC, Guedes MVC, Nóbrega MML. Construction of terminology subsets: contributions to clinical nursing practice. Rev Esc Enferm USP. 2013;47(4):962-6.

2. Doorenbos AZ, Juntasopeepun P, Eaton LH, Rue T, Hong E, Coenen A. Palliative care nursing interventions in Thailand. J Transcult Nurs. 2013; 24(4):332-9.

3. Coenen A, Doorenbos AZ, Wilson SA. Nursing Interventions to Promote Dignified Dying in Four Countries. Oncol Nurs Forum. 2007;34(6):1151-6.

4. Jo KH, Doorenbos AZ, Sung KW, Hong E, Rue T, Coenen A. Nursing interventions to promote dignified dying in South Korea. Int J Palliat Nurs. 2011;17(8):392-7.

5. Carvalho EC, Cruz DALM, Herdman TH. Contribuição das linguagens padronizadas para a produção do conhecimento, raciocínio clínico e prática clínica da Nursing. Rev Bras Enferm. 2013;66(n.esp):134-41. 